\section{a CASE OF PERMaNeNT CLOSURE OF THE JAW RESULTING FROM INFANTILE}

\section{PARALYSIS.}

BY W. EDWdRD MEADS, L.D.S.ENG., Bexhill-on-Sea.

ON July i2th, 1903, I was consulted dentally by a patient, Miss E. B., aged 28, to know if I could do anything to relieve her acute toothache. Upnn examination, I found the case was one of permanently locked jaws, and the following is the history and particulars of the case :

History. - The patient gave me the following history of her case. Then about $x 8$ months old she had a severe attack of whooping-cough and during convalescence she was given a hot bath. This was followed by two fits in quick succession, and she was taken to St. Marg's Hospital, Paddington, where it was found she had considerable paralysis upon the right side, affecting the lower jaw and the right leg. She remained at that hospital about eighteen months and the lower jaw became firmly closed. From that time to the present the patient had never opened her mouth. The patient had at various times been to several hospitals and seen many medical men. Besides St. Mary's Paddington, she had attended as an out-patient at The Children's Hospital, Great Ormond Street. Paddington Green Hospital, St. George's, St. Thomas's, and the Middlesex. She had also attended the West London Hospital, Hammersmith, for two months in each of three consecutive years. Last time she went there she was told that nothing more could be done except a general operation (I presume from the patient's remarks either excision of the condyle or Esmarch's operation was contemplated). Other medical men had confirmed this opinion. At one hospital they made seren attempts under chloroform presumably to break down adhesions surmised to exist at the articulation of the mandible. The patient had during these years eaten most usual foods, cut up finely, and with pepsinogen; and for years she had fed herself by pushing the food up between the upper and lower incisors (the former I conclude being somewhnt anteriorly protruded), and had worn down her finger nails in the process. Some five years before I saw the case a dentist had operated under gas, and had broken off the crowns of three upper and three lower incisors, leaving the roots still in. Through the aperture thus

State on Examination.-The patient, small and somewhat fragile in appearance, but otherwise apparently healthy, had her lower jaw almos immovably fixed, with the lower teeth in close contact with the upper teeth. The patient possessed a complete set of permanent teeth, which were interlocked and the jaw firmly fixed. On the right side the whole of the upper and lower teeth and the outer gums were covered by a shield-like mass of tartar, which the patient imagined was some bony development on her jaw. Most of the teeth were more or less carions, and the immeoiate cause of the patient coming to me was pain in or about the second upper right molar. The whole mouth was in most sevtic condition, with much tartar, spongy gums, and some pus exudation, while the breath of the patient was so offensive that it was becoming more and more detrimental to her in her business - that of a lady's hair-dresser and wig-maker. The patient had the crowns of three upper and three lower incisors missing; but the roots were still remaining. These were the roots left in from the operation referred to above. The patient had no temporary teeth or roots remaining, though how these were disposed of I could not ascertain. The patient informed me that her tem porary teeth were quite close together, though she thought not so locked as the permanent teeth. She had never had any temporary teeth extracted. There was no trismus of the muscles. and the jaw could be moved to the smallest possible extent by the patient. This movement was at the most not more than $\frac{1}{3 \pi}$ in. between the front teeth, and, though this was perceptible, for all practical purposes the lower jaw was immovably fixed. This slight movement, however, seemed to indicate that the muscles were not in a state of trismus or tension, and also that the fixture of the jaw was not due to ossification of the mandibular condyle. Beyond this very slight movement referred to no further movement of the mandible could be obtained by passive manipulation. Owing to the mandible never having been used it presented a remarkable example of non-development from non-use. The mandible was narrow, thin, and apparently, fragile, the horizontal ramus passing almost imperceptibly into the ascendlng ramus without the development of much angle. Neither was the general contour of the chin developed, there being practically no chin apparent, but passing from the neck to the face gradually. Both these abnormalities were more conspicuous on the right-the paralysedside than on the left, where more development of the angle had taken place. This atrophy, or rather non-development, of the lower jaw, the patient informed me, was not notjceable in earlier life, and did not become so till she was about $x 2$ years old. Although the proper contour of the lower part of the face was thus altered, especially on the right side, the angles of the mandible could be felt in their undeveloped state. At the angle there appeared to be either a nodule of bone or a groove on the lower edge slightly anterior to the angle, probably caused by the lack of development in this locality. The centre of the chin and lower part of the face were displaced towards the left side apparently about an inch-although this appearance was increased by the non-development of the right side- and the left corner of the mouth was sljghtly drawn downwards. On the face the masseter muscle; though small, showed some development owing to the slight active movement the patient could obtain in this muscle, but most of the other muscles in that region of the face and neck were in an undeveloped condition Two points of considerable significance were that there was no loss of Two poin anwere, either in the mouth or on the face, and no loss of hearing, and although I inquired I could not find there ever had been any such loss. The paralysed right leg was affected only from the knee downwards. Every other part of the body, except the right lower jaw, was normally developed, and there had been no deformity or loss of power in the right arm or hand. In early years the patient had walked with the right foot very much on one side and had.worn leg irons for some time. These, however, were discarded owing to constant breakages, and since then the leg had developed much more rapidly. When I saw the patient she was able to walk well in ordinary boots, though, the right leg being somewhat shorter, there was a limp. One other point was noted. For years before I saw the patient she had had a bilious attack on an average about once

had been extracted these ceased.

Diagnosis. - I had before seeing the case thought that some trismus of the muscles might have been set up by irritation from an impacted wisdom tooth or some such cause. This, however, was negatived by the extreme fixture of the jaw, even under passive manipulation, and the history of the case. I concluded that central paralysis had occurred as a result of the fits, and had caused paralygis of the right side. During the years that followed, owing to the non-use of the lower jaw, it had become flrmly fixed by fibrous adhesions at the mandibular articulation, but without ossification, thus allowing the very slight amount of movement that was perceptible.

Treatment. - Till I saw the patient except for the attempt, apparently, to break down the adhesions above referred to, no general treatment appeared to have been carried out, and the only suggestion was that mentioned by the patient, probably excision of the right mandibular condyle (which for financial reasons the patient was unable to carry out). Dentally the only treatment appeared to have been the breaking off of the six incisors also referred to above. Owing to the septic condition of the patient's mouth and the increasing liability to dental trouble from the carious teeth it seemed to me that, if possible, the first treatment was to remove all the teeth, which were not only useless for mastication, but most septic and unsightly. The patient had already suffered a great deal from the prospect of thereasingly frequent dental trouble in any or every tooth in her mouth was a source of considerable anxiety to her, since she had so repeatedly been told that no further treatment for this could be given, and it was impossible to treat it in the ordinary dental way. With the patient's consent, therefore, I proceeded to atiempt the extraction of all the teeth. During a succession of visits I scaled the teeth, as far as possible prescribing antiseptic mouth lotions from the commencement, and I extracted all the front teeth and the roots which which had been left n. This I carried out with a local (cocaine solution) anaesthetic hy podermically injected as $f a r$ as possible. The difficulty was considerable, as I could only inject the outer alveolus for the first extractions, and further I could not properly grasp the teeth with the forceps, but had to exercise a forward levering movement, breaking down the outer alveolus. This treatment I carried out with all the anterior teeth back to about the first bicuspids on either side. Then I found myself unable to extrast the teeth further back owing to the pain the required leverage gave the patient in the right condyle when forcing the teeth from their occluded position. In consultation with Dr. Deck, of $S t$. Leonards, I decided to try and extract the remaining posteric $r$ teeth under a general anaesthetic.

On September 27 th Dr. Deck administered A.C.E. to the patient, and in the course of an operation lasting over an hour I managed, with considerable difficulty, to extract about ten teeth by taking out the anterior teeth and then levering the next tooth forward and outwards into that socket. Owing to the haemorrhage and the condition of the mouth I left four of the posterior and mnst difficult teeth for a future operation when the mouth should have healed, and more space would have been obtained by absorption of the alveoli. On November 5 th Dr. Deck again administered A.C.E, and later chloroform, and I operated and removed the remaining four posterior teeth. These operations became increasingly difficult as I came to the posterior teeth, since the upper and lower second molars on either side were tightly fixed, crown to crown, with a space of not more than half an inch between the upper and lower alveoli. The difficulties were also increased by the risk of dropping a tooth on to the patient's glottis when in a recumbent position, since the space available rendered this more difficult to avoid and the ordinary methods of recovery almost impossible.

Result and Observations.

The teeth were all of good size originally, but almost all were decayed. Several of the roots of the teeth tended to be slightly bulbous, probably owing to pressure while developing and erupting. This pressure also accounted for the interlocking of the teeth and the slightly forward direction of the anterior ones.

The patient's mouth in the course of a month had very satiofactorily healed and the gums were in a healthy condition, with the alveoli absorbing. The jaw, however, remained
still firmly fixed without any further ability to close than to 
open it, either actively or passively. The health and comfort of the patient had also considerably benefitted by the operation.

The patient was instructed to exercise the muscles actively as far as she could by contracting them regularly and systematically for a few minutes several times a day. This she could do moderately well as regards the masseter and some of the infra-mandibular muscles. In this way, with the help of massage, etc., it was considered that in course of time, failing some more radical treatment, some movement of the mandible might be obtained.

On December 2oth I requested Dr. Lee to give his opinion on the case, and he kindly made a short statement of his views, as follows :

"As far as can be ascertained from the account your patient is able to give of herself, she had two attacks of 'convulsions,' which are the usual cause of infantile paralysis. The right leg was chiefly affected, and as there is now a difference in length of nearly an inch between the right and left. leg, and the right foot is partially paralysed, there is no doubt of the nature of the nervous lesion that occurred. So far as can be ascertained there was no paralysis of the muscles of the arm, and as the right hand has always been used freely, and preferably to the left, it may be concluded that the lesion which caused the paralysis of the right leg was below the cervical region of the spinal cord. The singular feature of your case, however, is the difference between the two sides of the face, and the paralysis that apparently has affected the muscles which are supplied by the seventh nerve. The same conditions as are presented in the right lower limb seem to be present on the right side of the face. As the sense of hearing on that side is perfect, and the sense of touch, we must conclude that the auditory branch of the seventh nerve, and the facial branohes of the fifth nerve have not suffered. It would be well to ascertain if you can whether the two attacks of convulsions followed very closely on one another, for it appears as if one, and probably the first, was the cause of the paralysis of the leg, while the second may have been a central cerebral lesion affecting the seventh nerve and causing the facial paralysis which has made your case one of great interest. It is probable that by gentle and continued treatment greater movement of the lower jaw may be obtained.

"It occurs to me that possibly the action of the muscles of the left side have been the chief cause of the jaws remaining closed for so many years. From a dental point of view the accurate diagnosis of such a case is important, as of course the prospects of improvement are far greater in your case than if there had been spastic paralysis and strong muscular tension had been exerted on the jaw.

$$
\text { " (Signed) }
$$

I have since ascertained that the two attacks of convulsions occurred within a week, though I have been unable to ascertain whether the leg was first affected or not.

The physical treatment mentioned by Dr. Lee was already being practised, and there are indications that the movement of the jaw may slowly increase.

\section{MEMORANDA: \\ MEDICAL, SURGICAL, OBSTETRICAL, THERA- PeUtidal, Pathologidal, Eto.}

\section{APPENDICULAR COLIC.}

ON August 26th, 1903, I was consulted at my house by a youth, E. $\mathrm{H}$., aged 19 , with reference to a pain in his side felt for the first time five days before; since then it had kept "coming and going," being sometimes very severe. On being asked where the pain was he placed his finger exactly over McBurney's point after fecling about in the neighbourhood for a few 8econds. There was no history of anterior appendicitis, but $I$ at once sent him home to bed.

State on Examination.- On the following day I found his temperature and pulse normal, but a distinct tenderness over the above-mentioned spot, the resonance being tympanitic and a gurgle produced on pressure. There was no enlargement of the spleen, nor could I detect any constitutional disturbance. During the following week I treated the condition by the administration of carminatives, the pain being sometimes absent for a day and sometimes for two days, but returning on the third day. As he did not desire to remain in bed, and, as the temperature and pulse still continued normal, he was allowed to go about the house. This state of affairs continued for two more weeks without any rise in temperature or alteration in pulse; but towards the end of this period the attacks became very severe, the pain being excruciating and producing almost a state of collapse; otherwise there was no alteration in the local condition. He was now kept in bed, copious soap-and-water enemata being given, 5-minim doses of nepenthe every four hours, together with carminatives. This treatment was continued without effect until the following Friday, there still being no elevation of temperature or alteration in pulse. Although there were no apparent constitutional effects being produced except during the attacks of " colic," it became evident that something surgical would have to be done in order to relieve the condition and enable him to follow his occupation. After explaining matters I therefore removed the appendix the following morning. His convalescence was a little protracted owing to the development of a tricuspid murmur, which latter, however, disappeared with extra rest in bed; except for this he made an excellent recovery, as one would naturally have expected, there being no adhesions, and the operation, therefore, a comparatively simple one.

REMarks.- On cutting open the excised appendix a darkbrown, semi-solid, foul-smelling substance oozed out. In the interior were found two or three small pockets containing a similar substance with faecal odour, and separated from each other by distinct constrictions free from such contents. Two things struck me at once, namely, the risk which would have existed if operative interference had not been undertaken, and the uselessness of medical treatment in such a condition. Had the doses of opium been large the only symptom would probably have been masked, and a pericaecal abscess, or maybe fatal peritonitis, have followed.

I think the lessons to be learned from this case are obvious and worthy of remembrance.

Cardiff.

$$
\text { W. Hesketh Evans, M.D. }
$$

\section{SPORADIC CRETINISM.}

Cretrinism being uncommon in England, the following account of what I believed to have been a sporadic case may be of interest:

History.-The patient had the following history: She was not a "bright" infant, and was 8 months old before she appeared to take an interest in her surroundings. It was longer than usual before she could hold up her head when she was nursed; she did not begin to crawl until she was ${ }_{5}$ months old, was 3 years of age before she could stand, and only began to walk at $3 \frac{1}{2}$ years. The "head openings" closed early; the first teeth came at 2 years of age, and dentition was not complete at $4 \frac{1}{2}$ years. She began to protrude her tongue as an infant, but there was no unusual dribbling. The child did not "crow or talk" like other babies, and could only say a few words at the time of her death and could not make a connected sentence. The appetite was usually good but not abnormal; she was a "clean and good child." She did not play as other children, but latterly developed powers of mimicry and wanted to do what other children and people did.

State on Examination.-When I first examined her she was 4 years old, was unable to talk, and could only walk slowly and imperfectly. She was puffy, fat, of ashy-yellow colour, had a coarse skin, a swollen abdomen, and was of stunted growth. The head was larger than normal, that is, it was expanded at the sides, and flattened at the top and somewhat "bumpy;" the forehead was broad, the eyes wide apart, the nose flattened and broad, indeed the face appeared flattened; the lips were swollen, the tongue large and nearly always protruded, the palate was high-arched; the thyroid was deficient, and there were well-marked supraclavicular swellings. She was mentally " slow," sometimes easily amused, not passionate, generally "good." She was languid and apathetic; she could understand and be interested in many things which delight other children of the same age, but everything seemed too much trouble to her. Her muscular power was feeble, but the palmar reflex, as shown by tickling, was apparently normal.

Progress. - The child was put under thyroid treatment, and she improved considerably; whether due to the drug or not, she certainly gained in mental and physical vigour; she walked better, used more words, made herself better understood, took interest not only in childish, but other things among her surroundings. The treatment, however, was intermitted. When I next saw her she was suffering from purpura, to which she succumbed.

I made the diagnosis of cretinism because the child had none of the deformities or degenerative stigmata so common in idiocy, such as asymmetry of head or body, squint, nystagmus, or look of vacancy; her ears were perfect, there was no fissure, no supernumerary ear, or Darwinian tubercle. On the other hand, she had the broad, flattened head, the wide-set eyes, the flattened nose, the abnormal-sized tongue, the high-arched palate, the late dentition, walking and speaking of the cretin, as well as the elastic lumps between the sterno-mastoid muscles and the clavicles. A further point in the diagnosis was the improvement, both mentally and physically, which followed the administration of thyroid. The skull was by no means microcephalic; it was modified in shape, expanded at the sides, and flattened at the top, but "bumpy"- that is to say, owing to a precocious union of the bones, the growing brain had a tendency to cause a compensa. 